\title{
EL NEO-IDEALISMO Y EUKEN
}

FILOSOFIA DEL SIGLO XIX Y EL NEO-IDEALISMO.

$\mathrm{Si}$ la generalización len las ciencias naturales, no realiza ampliamente la función ordenadora que le está encomendada, por escapar a su esfuerzo elementos contingentes; en la historia, solo pretende establecer meridianos aproximados y orientaciones, sobre la multiplicidad de corrientes y complejas direcciones de una época.

El siglo XIX se ha dicho, es el siglo del positivismo. Pero tal afirmación es cierta en lo que tiene de preponderante y original, más, al lado de las corrientes realistas, coexisten direcciones idealistas que en la historia de la filosofía no dejan de subsistir.

En Francia, durante la primera mitad del siglo, Comte, con su poderosa personalidad, predomina en el ambiente filosófico. Su positivismo, original, produce una renovación benéfica contra el eclecticismo, ayuno de fuerza e interés. La escuela positivista, influye todavía a mediados del siglo XIX, ampliando sus dominios desde el año 55, al campo de la literatura.

Los positivistas de esta época, demuestran cierta proclividad hacia el idealismo. Taine, filósofo y literato realista, reconoce su campo de acción a la metafísica y concibe la religión, como la evocación de una inspiración artística. En Renan su literatura y su filosofía, se reclama de una inmensa inspiración hegeliana. El espíritu, dice, evolu- 
ciona en el proceso cósmico y en el devenir temporal, por eso Fouillée dice "que para Renan, la verdadera teología, es ciencia del mundo y de la humanidad ". (1).

El positivismo dogmático, a fines del siglo, inicia su irreparable decadencia. Se reconoce la sustantividad del espíritu y la cultura, como realidades auténticas, y el realismo se amplía trasladando los métodos de las ciencias naturales al campo de la sociedad, de la vida y del espíritu .

La aplicación del método histórico a todas las ciencias y a la filosofía integra las concepciones ideológicas de la época, dándole una trayectoria continuada con la cultura del pasado.

A fines del siglo XIX, desde el año de 1890, se inicia en Francia el movimiento neo-idealista representado por las señeras figuras de Renouvier, Ravaisson y Secretan, habiendo asistido los dos últimos, como alumnos de Schelling, a la Universidad de Munich.

La influencia de Coussin desaparece y el idealismo opone el pensamiento de Biran, a las sugestiones de la filosofía ecléctica.

Los románticos alemanes producen honda impresión en el ánimo de ésta nueva filosofía. Ravaisson, influído por Schelling, admite la posibilidad de conocer el absoluto por la intuición intelectual y, por su filosofía sentimentalista e intuitiva, se señala como el precursor del neo-romanticismo francés.

La idea fuerza de Fouilleé y el sociologismo de Guyau los dirige también una fuerte preocupación idealista.

Pero es a fine $B$ del siglo $X I X$ y] a principios del XX, cuando aparece en Francia el nuevo movimiento idealista, siendo Boutroux, Bergson y Hamelin los voceros de esta nueva filosofía.

El problema que preocupa principalmente, es el problema de la libertad y el determinismo, por eso Parodi dice: "que en Francia y en particular en el siglo XIX aparece como el problema filosófico por excelencia" (2).

La influencia de Hegel sobre Hamelin es manifiesta. En su tesis "Essais sur les Elements principaux de la Representation" que es una réplica racionalista de la tesis de Bergson, constituye el "más vasto y completo esfuerzo del idealismo contemporáneo", añade Parodi.

En la filosofía francesa, los problemas estudiados son dispersos, preponderan los relacionados con la psicolgia, moral y filosofía de las ciencias, pero faltan las visiones unitarias del mundo, del hombre y de la realidad total del universo.

Italia, representa en este siglo, cierta discontinuidad en su pensamiento filosófico debido, seguramente, a su proceso político de renovación y de lucha. En esta época, a principios del siglo XIX, solo apa-

(1).-Filosofía Contemporánea. pág. 78.

(2). - La Philosophie Conemporaine en France 5 ed. 1925 p. 161. 
recen dos figuras que eran desconocidas en la filosofía europea, pero que han merecido ser traídas a la consideración del mundo, en el curso de la Universidad de Nápoli, el año 1861, por Spaventa y son: Gioberti y Rosmini.

Para Gioverti, la filosofía tiene por objeto el estudio de la idea que es "su principio y objeto". (3) Sus disquisiciones metafísicas sobre la intuición y la dialéctica le dan un matíz marcadamente romántico. Sólo como una hipérbole propia del exagerado nacionalismo de Spaventa, y que Guido de Ruggiero reafirma, se puede sostener la similitud y comparación de Gioberti con Fichte, Schelling y Hegel.

Rosmini, si bien no tiene la importancia del anterior, debemos señalarlo por su punto de vista renovador y por su inclinación religiosa como el precursor del modernismo católico.

Sin embargo, la filosofía de estos dos pensadores no ejerce ningura influencia benéfica en Italia, se les olvida, la conciencia filosófica de la época es anémica y después de la guerra de 1848 a 1849 "la fjlosofía italiana parece presa de una invencible sonnolencia". (4).

Aparecen filósofos de escaso valor, como Mamiani, Ferri, Bertini y Ferrari que acusan una débil personalidad.

La influencia del positivismo francés, con Comte, y el inglés, con Stuart Mill y Spencer se dejan sentir y producen la conversión de Ardigo, del catolicismo al positivismo.

Su filosofía es un esfuerzo que parte de la concepción del positivismo para llegar a la unidad del ser, acentuándose su tendencia crítica.

La influencia de Kant en Italia, se manifiesta en el principal representante de la lógica Masci. Es en Martinetti, en donde se marca la trancisión del criticismo al idealismo absoluto.

El idealismo en Italia, está representado por Spaventa y se amplía y profundiza en los dos más grandes rieo-hegelianos del presente Groce y Gentile a los que han seguido una reacción anti-hegeliana con Aliot: Rensi y Monacorda, filósofos del siglo XX de la posṫ-guerra, y de los cuales no nos ocuparemos por ser extraños a nuestro tema.

La filosofía inglesa, presenta un caso único por su desarrollo original. Pueblo netamente realista, cuya filosofía empirista influye sobre toda la filosofía del mundo occidental con Mill y Spencer, realiza durante este tiempo, un movimiento idealista independiente que es uno de los más importantes de la filosofía contemporánea.

Ya en el siglo XVIII la influencia platónica cristiana, había formado la escuela intuícionista en que la preocupación moral ocupaba

(3).-Spaventa: Filosofía Italiana nell sue relazione con la filosofía Europea p. 184.

(4).-Guido de Ruggiero.-La Filosofía Contemporánea. 1929. 3ra. Edic. Tomo II. Cap. 109. 
un lugar preponderante y que se produjo como una reacción contra el utilitarismo de Benthan .

Coleridge que fué influido por el movimiento romántico alemán, caracterízace por su notable pensamiento religioso y se le considera como el iniciador del movimiento católico inglés .

La filosofía de la personalidad de Carlyle y su interpretación de la filosofía, como una lucha espiritual, lo anticipa al movimiento idealista actual. Coleridge y Carlyle son los precusores del idealismo inglés.

Es el neo-hegelianismo, renovado y con caracteres nuevos, el que va a imprimir su carácter al idealismo inglés. Sterling, Green y Bradley son sus principales representantes en Inglaterra, Emerson y Royce en Estados Unidos.

Green, desde el año 1878, influye poderosamente en la juventud inglesa, su platonismo, con sus medulaciones líricas, le imprime una honda emoción espiritual.

Su espiritualismo absoluto tiene caracteres relativos, cuando se refiere a la realidad circundante de la experiencia .

Sin lo absoluto, no sería concebible lo mudable y lo relativo. $Y$ sin lo relativo, el absoluto se diversificaría en un pluralismo. La conciencia que es la unidad, presente a todos los cambios y a lo relativo, es identidad espiritual y eterna. Es Dios.

El filósofo más grande del movimiento inglés, es Bradley. Inicia su investigación sicológica, refutando el atomismo y establece con poderosa visión la concepción unificadora y totalizadora de la conciencia. Apesar de su intelectualismo, encarna el problema de la contradición y su personalidad,udominaliasoprimeras décadas del presente siglo.

El movimiento posterior a Bradley, no nos interesa por pertene cer al presente siglo, pero haremos notar que el idealismo perdura en Inglaterra con la publicación en el año 1902 del notable libro "Personal Idealismo" escrito por ocho autores que son: Stuot, Rashdall, Schiller, Sturt y el notable divulgador de Euken, Gibson. Esta obra encierra "un llamamiento a los intereses y valores humanos para el establecimiento de la verdad" (5).

A pesar del nacionalismo filosófico que creía Guido Ruggiero que impera en la filosofía del siglo XIX en Alemania el pensamiento de dicho pueblo es el que dirige la especulación iedalista de la filosofía europea .

La filosofía del siglo XIX en Alemania es tan original y tal es la amplitud de su panorama, que sólo nos ocuparemos del movimiento (5).-Arthur Kenyon Rogers English and Amlerican Philosophy Since 1800
New York 1923 pág. 322 . 
ideológico inmediatamente anterior al neo-idealismo, del que Euken, es el iniciador y la primera figura.

El notable filósofo y profesor de la Universidad de Tubinge, Oestereich, (6) al estudiar el desenvolvimiento de la filosofía alemana durante este siglo, lo divide en tres períodos. El primero, tiene su punto culminante en el año de 1794 con la teoría de Fichte y concluye en el año de 1831 con la muerte de Hegel. Esta es la etapa más brillante de la filosofía alemana con los grandes sistemas especulativos y la filosofía romántica en que se destacan personalidades de tanto relieve como Fichte, Schelling y Hegel; en que aparece el sistema panenteista de Krause, la filosofía de Schlaiermacher y las profundas disquisiciones del voluntarismo pesimista de Schopenhauer.

El segundo período, se inicia en el año 1831 , y concluye en el año 70. En esta época se desenvuelve la escuela de Hegel que se dividió en las llamadas derechas e izquierdas hegelianas.

Las derechas hegelianas, están representadas por Rosenkranz y Erdmann y patrocinadas por Federico Guillermo IV que, para oponerse a las izquierdas hegelianas de Straus y Fuerbach, llama a Schelling para que dicte un curso de en la Universidad de Berlín, pero su edad y decadencia mental lo llevaron al fracaso. Era un esfuerzo por conciliar la doctrina de Hegel con la Iglesia.

Las izquierdas hegelianas, eran de tendencias eminentemente radicales y sus representantes más señalados son: en la filosofía religiosa; Straus y Fuerbach, y en el campo-social Marx y Stirner.

Es, en el terreng de la historia de la filosofía, donde Hegel va a ejercer una influencia provechosa. La historia de la filosofía, adquiere los caracteres "de un sabefipreciso yndrdenado en que aparecen los estudios sobre la filosofía griega y la historia de la filosofía moderna de Zeller y Fischer. Se crea la escuela de Tubinga, por Baur que tan grande importancia ha tenido en el estudio de la historia de las religiones, surge el materialismo histórico de Marx y Engels, que dá nueva conciencia y precisión a las doctrinas socialistas y comunistas, y la nueva concepción de la sicología del pueblo de Lazarus y Steinthal que inicia la filosofía cultural de nuestra época.

La psicología, de tendencias marcadamente empiricistas de Fries, Herbats y Beneke, que se desenvuelven durante la época del romanticismo, influyen en la filosofía de los años 50 y 70 para iniciar la reacción contra el romanticismo, en el materialismo, de Büchener y Molechott.

El monismo perdura apesar del materialismo. Lotze, fuertemente influído por el romanticismo, se puede considerar como el último filósofo idealista de antigua cepa, y como filósofo de transición entre el

(6).-T. K. Oestereich: Die Deutsche Philosophie Des Neunzehnten Fahrhunderts und der gejenward. Berlin. 1923 p. 2 . 
idealismo romántico y el mecanismo positivista. Monista por termperamento, pretende unir la naturaleza al espíritu. Fechner, como creador de la psico-física, pretende establecer una correspondencia constante entre el cuerpo y el espíritu, y Hartmann, con su filosofía de lo inconciente y su pesimismo influído por Schopenhauer, une a una intensa inspiración realista, profundas disquisiciones sobre lo irracional en el universo.

El positivismo francés y el utilitarismo inglés, dominan el pensemiento alemán. La filosofía, es considerada como un estudio inútil y sin contenido propio. Pero son precisamente los científicos más connotados de la época, los que han de sentix la necesidad de una nueva filoscfía que les pueda dar una visión unitaria y sintética del mundo y del universo, los que han de ser los colaboradores de la nueva filosofía.

Desde el año 1860 , se vislumbran los primeros esfuerzos del neoidealismo. Es en el año 70, más o menos, en que el neo-idealismo aparece, e inicia el tercer período de la filosofía alemana según la clasificación del profesor Oestereich ya citado.

En esta época se nota en Alemania un prodigioso desenvolvimiento de la filosofía, de la historia y de la filosotía de la cultura. Aparece la solitaria figura de Nietzsche que fustiga con acrimonia la satisfacción producida por los progresos técnicos y positivistas de la época.

Aunque el progreso material, traído por la política de Bismark, invade las poblaciones de Alemania "la vida interior parecía sembrada de graves confuciones que pecola pocotiban haciéndose conscientes" (7). En estos momentoscien lquéesev tenia como una conquista satisfactoria y plena, los progresos materiales realizados en el mundo de la realidad, es que aparece la señera personalidad de Euken como portavoz de una nueva filosofía, como propulsor de un nuevo movimiento, en que, el espíritu tiene primacía sobre todas las adquisiciones de la realidad circundante.

Es el iniciador y fundador del neo-idealismo alemán.

La clasificación de la filosofía de Euken que hemos hecho parece ser la que responde perfectamente a un criterio filosófico y está de acuerdo con la mayor parte de los críticos alemanes como Külpe, Vorlander y Windelband. Otros historiadores de la filosofía han hecho distintas clasificaciones. Así Messer, lo coloca en lo que llama la "filosofía protestante" (8) pero esta clasificación nos parece que responde a un criterio más religioso que filosófico, pues el concepto del protestantismo no responde a ninguna dirección filosófica actual.

Guido de Ruggiero lo llama a Euken "corifeo de la nueva meta-

(7).-Rudolf Euken.-Recuerdo de mi vida. pág. 454.

(8).- Agust Messer.-Filosofía Actual.—Cap. II pág. 79. 
física trascendente" (9), pero esta clasificación tampoco señala lo que tiene Euken de original y nuevo y sólo constata unos de los aspectos de la filosofía.

\section{CAPITULO II}

\section{VDA DE EUREN (1)}

La obra de un gran pensador, no sólo se perfila por la obra que ha escrito, sino también por su vida, que nos muestra las influencias que durante ella ha tenido y la génesis de sus estados espirituales.

Euken, nació en la ciudad de Aurich, Frisia Oriental, el 5 de Enero de 1846. De niño, sufrió dos accidentes que estubieron a punto de quitarle la vida, y la muerte de su hermano y de su padre, niño aún, hicieron su carácter serio y triste.

Emprendió viaje con su madre, y en el camino de Gifhon a $\mathrm{Ce}$ lle, un rabino le predijo que "viajaría por países remotos y haría mucho en servicio de Dios".

La influencia de su padre en su carácter, no fué poderosa. Su afición a la aritmética, estadística y comercio se la debe a él. Pero, la influencia de su madre fué grande, a tal punto, que Euken dice "puedo decir que me comunicó sus rasgos esenciales "(2). Pero un tío suyo, hermano de Jsur madre,cyncombcella criado en un ambiente intelectual y artístico, influyó de manera poderosa.

En conversaciones y frecuentando su biblioteca, encontró la oportunidad de iniciar su cultura intelectual. Su madre criada en este ambiente deseaba que su hijo se educara con esmero y mediante algunos ahorros, lo puso en el gimnasio de Aurich, de donde conservó gratos recuerdos.

El ambiente conservador del colegio, influyó seguramente a que por reacción, se manifestara su espíritu liberal que también era el de su familia. Wiihehon Reuter, director del colegio y aunque espíritu conservador, influye en su espiritu en "las grandes contradicciones de la vida y el contenido espiritual del almă" (3) .

Aficiónase a la filología clásica y a la filosofía. Ocupa el primer

(9).-Filosofía Contemporánea pág. 128.

(1).-El presente capítulo sigue los linamientos autobiográficos consignados en su obra, "Recuerdos de mi Vida", escrita el año 1929. Los datos posteriores pertenecen a otras fuentes.

(2) .- Rodolfo Euken; Recuerdos de mi Vida. pág. 382.

(3).-Rodolfo Euken; Recuerdos de mi Vida. pág. 398. 
puesto en su clase y "me acometió, dice Euken, una sed de saber que me hacía devorar diccionarios enteros" (4).

Las matemáticas fue su ciencia preferida, pero las contrariedades de la vida, su natural pensativo y su compresión para los problemas humanos, tenían que dirigir su atención a los problemas filosóficos y religiosos. "Mi niñéz, dice, tuvo poco sol, estubo sembrada de dificultades" pero la esperanza le ilumina y tenía la convicción de que un poder supremo regía así mis destinos como los de la humanidad entera y que podía confiar en él" (5).

A los 16 años de edad, concluyó sus estudios de bachillerato, a los 21 años escribió un trabajo sobre las Tusculanas de Cicerón que, según su profesor Reuter, "anunciaba las mejores disposiciones" (6).

El aislamiento y la tendencia a filosofar le atraían, tendencia que fué combatida por su madre y a sus instancias dice Euken, es que debió el no haberse convertido en un "erudito intratable". (7).

Se le hacen entonces concientes contradicciones y luchas interiores; los problemas de la humanidad le preocupan y la religión, tal como la había visto en su pueblo, no le elevaba el espíritu. Le decepcionaba el especialismo de los profesores de Cotinga. Sauppe, Curtius, Von Leutch y Zeicmuller influyen en él. No lo satisfizo Lotze con su filosofía erúdita y su poca preocupación por el problema de la vida. Teichmuller, le animó para que escribiera un estudio sobre Aristóteles que ya había iniciado, y Lotze le disuadía de su empeño por parecerle estéril. Las escursiones y viajes que realizaba contribuyeron a la elevación de su espíritu: La filología, la filosofía, las ciencias matemáticas y naturales le disputaban su afición. Pero se decidió a la filología por la índole de sus estudios. La afición filosófica era tan poderosa, que en su estudio filológico sobre Aristótoles le analizó también desde el punto de vista filosófico.

Fué su tesis doctoral que la presentó en 1866 a los 24 años de edad. Se dirigió a Berlín, donde fué protegido de Trendelenburg. Perteneció al seminario pedagógico de Boekh y frecuentó el círculo de Krause. Gracias a la protección de Hoffmann, fué nombrado profesor de Spohien-Ginnasiun y pudo permanecer en Berlín.

Enseño en algunos gimnasios, en la Escuela Real de Husun (Schelesvvig) en 1869 en Friendench-Ginnasiun; y en 1869, solicitado por Mommsen, hermana de Teodoro Mommsen, pasó a Franfort. Fué amigo del historiador católico Janssen a quien estimó mucho y de quien afirma recibió influencia y de Wedewer. La guerra del 70 lo encontró de regreso a su país natal. En el año 1871 fué nombrado profesor de

(4).--Rodolfo Euken; Recuerdos de mi Vida. pág. 399.

(5).—" " " " " " pág. 400

(6).— " " " " " " " " pág. 403 .

(7).. " " " " " " pág. 404. 
Basilea a los 25 años de edad en reemplazo de Teichmuller en la cátedra de filosofía y pedadogía siendo compañexo de Buckhardt y de Nietzche. En el año de 1872, murió su madre. Las cuestiones de la cultura moderna le preocupan. Aristóteles, dice Euken, con todo lo que el me ofrecía sólo era un puente para pasar a otras regiones más dilatadas (8) y agrega; "mis aficiones me inclinaban a Platón" (9).

En las conferencias que daba en Basilea, estudiaba el problema filosófico contemporáneo. Se relaciona con las ideas socialistas, pero su crudo positivismo, le desagrada. Durante el año 1872 , se de dicó a la lectura de los padres de la Iglesia y se preocupó por la concepción de la vida. Influyeron sobre él, Gregorio Nacianceno y San Agustín. Entonces Lebuck le ofrece una cátedra en Jena en 1874 uno de los más altos focos de la cultura alemana, donde se dirigió. Tuvo por compañeros a Hasse, Lipsius y Haekel, "papá del evolucionismo" como le llamara Papini. Los años que siguieron al triunfo de Alemania en la guerra del 70 trajo a Alemania lo que llama Euken la "cultura del trabajo" (10) o sea, como en el estudio de su doctrina veremos, el predominio o el esclusivo valor a los progresos de la materia, sin preocupación de los valores del espíritu. El gobierno absoluto se impone, los intereses económicos preponderan, y el hombre es considerado como un medio de resurgimiento colectivo material. El espíritu del hombre no se tenía en cuenta y la unión interior y espiritual no existían. El idealismo de los antiguos moldes caducaba; el positivismo y el materialismo erandas únicas filosofías que parecían posibles y que domingban ebambiente. Era un estado de astenia espiritual" (11).

Su filosofía de la vida se va perfilando en un sentido idealista, poniendo al espíritu en la cúspide, sin vulnerar los derechos de la naturaleza. Rechaza la preponderancia del intelectualismo y el problema histórico le preocupaba. En 1878, aparece sus "Conceptos Fundamentales de Actualidad" traducida en 1880 al inglés y en su segunda edición, aparecen los lineamientos más firmes de su filosofía.

En 1879, aparece su "Historia de la terminología filosófica" donde estudia la evolución de los conceptos a través de la historia y que después le había de servir para precisar los términos de los problemas que estudie. Escribió en la "Gaceta de Amsburgo" pero estaba algo alejado del elemento joven. Viajó por Holanda, Flandes e Italia .

En 1882, casó con Irene Passovv que, sin ser una destacada mentalidad, ejerció influencia sobre su pensamiento. "Para mi pensamien-

(8) - -Rodolfo Euken; Recuerdos de mi Vida pág. 443.

(9)._" " " " " " pág. 444

(10)— " " " " " " " " " pág. 454 .

(11)_ " " " " " " pág. 456. 
to filosófico, dice Euken, era una gran adquisición; con ello ganó mayor plasticidad y frescura".

En 1883, publicó su "Prolegómena" y en 1888 "La unidad de la vida, del espíritu en la conciencia y en acción de la humanidad". En el grueso público, no tuvo resonancia la obra, pero Naptorp y Seydel la estudiaron. El tema de algunas conferencias dadas en Basilea, le sirvieron para su obra "Los Grandes pensadores y su teoría de la Vida" publicada en 1890, teniendo en la actualidad en Alemania 18 ediciones y traducida a casi todas las lenguas cultas.

Escribe también "Las imagénes y las comparaciones en Filosofia" y una memoria en el jubileo de Eduardo Zeller sobre Comte y el positivismo. En Alemania con la influencia Nietzche resurge el subjetivismo.

En 1896 escribe "La lucha por un contenido espiritual de la vi$\mathbf{d a}$ " que en la actualidad tiene cinco ediciones. La preocupación religiosa y como dice Euken, la gran insinceridad del estado actual en materia de religión, le hizo escribir "El contenido de verdad en toda religión" (1901) obra la más personal según dice Euken, donde hace después de su acostumbrado estudio crítico del problema en el pasado y el actual, un estudio sobre el Cristianismo y la religión característica. Produjo muy buena acogida tanto entre liberales como católicos y Norstron se ocupó de ella. En 1900 dirige las fiestas centenarias de Goethe.

Dió conferenciaśs en Turingia, Brementy Hamburgo. En 1903 aparecen una colección de artículos sobre la filosofía y la vida. La Facultad de Teología de Giessen le nombró doctor "honoris causa".

En 1904, le proponen remplazar a Siwart en Tubinga. A solicitud de los filandeses les presta ayuda en sus preocupaciones nacionales. Dió conferencias en Utrecht, Amsterdam y Luden.

En 1907, escribe "Ensayo sobre una nueva concepción de la vida" y "El problema principal de la filosofía de la religión en la Actualidad" que tuvo cinco ediciones. En 1908 publicó "El sentido y valor de la Vida" que ha tenido 9 ediciones y que está traducida al castellano.

El año de 1908 se le distingue con el premio "Nobel" siendo con este motivo centro de atenciones, y festividades y aplaudido universalmente.

Se dirige a Inglaterra en 1914 y publica su obra "Podemos aún ser cristianos?" En 1912 va a Estados Unidos de Norte América donde dá conterencias en Cambridge, Bostón, Filadelfia, Baltimore. La Universidad de Columbia, le concede el título de "doctor of letters". la de Siracusa "doctor of human letters", la de New Yiork "doctor of law". En New York encuentra a Bergson.

Se funda en New York una "Asóciación Euken' 'en Gelligsburg 
"Euken Club". Escribe "Hacia la comunión de los espíritus" donde establece la necesidad de la espiritualización de Allemania. Reunió en Darmstadt en Marzo de 1914 una sociedad con ese objeto y recibe invitaciones de Inglaterra, Francia, Bulgaria, Australia, India, Japón, China, la Universidad de Columbia, y se disponía a dirigirse a la China y el Japón cuando la guerra le desbarató sus planes.

Declarada la guerra, Euken cree su deber dedicar sus energías a sus compatriotas y justifica la situación de Alemania que "estaba en su derecho de ir a la guerra y defenderse de todos los que la atacaban" (13) y firmó el manifiesto de los intelectuales de su patria que produjo gran sensación en el mundo.

El deber de los intelectuales de Alemania era fortalecer los ánimos, dice Euken, y agrega "la provocación habia partido de los aliados y la actitud de Alemania era de legítima defensa.

Dió conferencias políticas y sintió los profundos latidos del alma nacional. Los problemas nacionales le preocupan, escribe "La significación histórica del espíritu alemán”. "Los representantes del idealismo alemán" y su ardor patriótico. no lo cegó al dictar sus clases sobre la filosofía francesa e inglesa a quienes hace imparcial justicia.

La guerra, dice Euken, le provocó hondas reflexiones, el bien y la verdad no reinan en el mundo y "esta lucha encarnizada no dá señales de corresponder a un orden moral" (14).

Durante la guerra escribe "El hombre y el Mundo" convencido que es necesario un esfuerzo por unificar el estado de espiritual anarquía reinante, sin que por ellocie ereaCcapazrde'realizarla en su obra sino sólo de "echar los cimientos del edificio, trazar bosquejos de firmes contornos y ofrecer una buena orientación".

Una fuerte pulmonía le ataca en 1918, de la que felizmente salvó: La revolución alemana, le presenta problemas a su consideración. Escribe "Que recurso nos queda", "La libertad alemana", "El socialismo y su concepto de la vida" en 1920. En este año se jubila de las actividades universitarias.

Se funda, en Jena, la "Sociedad Euken" cuya primera reunión tuvo lugar el 6 de octubre de 1920, para lo cual escribió "Nuestras pretenciones en la vida". Sus obras, en fin, han tenido una divulgación mundial y en 1920 son traducidas al chino.

"Sólo le queda, nos dice en su auto biografía, invitarnos a la renovación y al trabajo mientras es de día; considerar toda transacción como un delito".

En las últimas palabras de su autobiografía, como despedida a sus lectores, no podía faltar un recuerdo lírico a su madre en un gesto de suave y romántica nostalgia. Recuerda a su madre que determinó 
un gran fondo en su alma no faltando la consagración del dolor. A su esposa, que con su alto espíritu artístico tiene su mente puesta en altos fines; y por último, a sus hijos que convierten, como el dice, su hogar en un microcosmo de la vida del espíritu".

Pero la vida de Euken no termina con su auto biografía. Apesar de los años, no ha desaparecido en él la energía y la actividad. En 1924 inicia la publicación del periódico "Die Tat" (La acción) en coloboración de su esposa. La vida se iba extingiendo y apesar de la edad, su espíritu se renovaba constantemente, demostrando que el espíritu es eterno como eterno son sus obras.

"Cuando al fin de mi camino, dice Euken, vuelvo los ojos atrás y considero el trabajo de mi vida, debo reconocer, agradecido, que no he vivido al azar sino que mi esfuerzo tiene una coherencia interna".

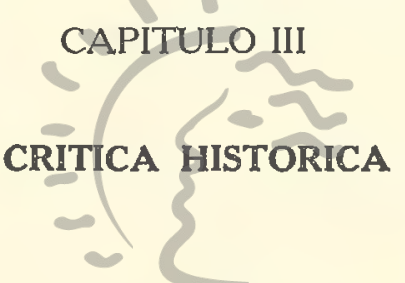

En su desenvolvimiento filosófico, Euken, ha pasado de la historia a la filosofía. Sus primeras-bbras, asílo acreditan, y la forma de tratar los problemas, Jla çonfirman.elil estudiarel problema filosófico, su visión histórica, le da gran profundidad y amplitud $\mathrm{y}$, la interpretación de las épocas pretéritas, las perspectivas del povenir.

Sus obras las divide teniendo en cuenta las dos grandes trayectorias de la vida. La primera, es la parte crítica que se refieer al pasado; la segunda, la parte constructiva que, teniendo en cuenta los vacíos y lagunas del presente, construye con poderosa visión, los lineamientos de la filosofía dirigida hacia el porvenir.

Es necesario que analisemos y revisemos el espíritu de los grandes pensadores, que estos héroes del pensamiento no pasen ante nuestros ojos como sombras amorfas y faltas de vida sino que sus figuras, adquieran cuerpo y sangre". Y que sus creaciones "alimenten nuestra labor propia" (1).

Su obra filosófica, no pretende ser como la de Hegel la conclusión y el remate de toda la filosofía, sino que sañala lineamientos, insinúa direcciones, que la posteridad es la llamada a desenvolver.

Para Euken, la filosofía es la aportación espiritual de una época, la cual, debe auscultar y satisfacer las necesidades espirituales.

(1).-Rodolf Euken; La vida, su valor y significación. pág. 13. 
El estudio de su filosofía, exige pues que analisemos su interpretación histórica llena de sugestiones interesantes y de perspectivas luminosas .

El mindo antigto, consideraba la vida como dirigida por fuerzas religiosas o divinas, desconocienclo el valor de la vida inmediata, para concentrarla en la vida del espíritu. De esta concepción, nació el cristiazismo, en que poncera el ideal de justicia y sobre todo de amor. Se considera, como digno de valoración, lo que se aleja de la realidad exterior, e interiorizándonos, establece, "una dirección parcial deł hombre, del espíritu para el espíritu" (2).

Pero la relación espiritual, hacía patentes los conflictos entre la aspiración espiritual y la vida exterior, de allí el pecado que denominaba dolorosamente sobre las conciencias.

La vida contenía así, intensas conmociones de tragedia y violentos arranques de pasión. Del dilema que se planteaba entre la vida exterior y la vida del espíritu, surgían formidables figuras de santidad, emblemas de la vida cristiana.

Frente a la organización de la vida religiosa, encuentra Euken, en el mundo antiguo, la organización de la vida según el idealismo inmanente de los Griegos. Esta concepción, se diferencia de la anterior, en que el reino del espíritu y el de la perfección no es exterior al universo, sino que está en el interior, animando y presentándose como el ideal por realizarse. Entonces el hombre, no está como en la concepción anterior, en pugna conla reâlidad exterior, sino gue su misión está en realizar el ideal por medio de la creación espiritual.

Si bien no hay oposición entre la naturaleza" y el espiritu, hay una diferencia de grado que los distingue y delimita.

El mundo, viene a ser el medio para el desarrollo normal de la humanidad, en oposición al cristianismo que lo conisdera como lugar de pecado. La ciencia y el arte, sirven para el desenvolvimiento de esta concepción vital. Había entre el cosmos y el hombre, una relación inmediata en que el hombre ocupaba el centro y la coronación del desarrollo universal. La relación entre los distintos componentes del todo, se unían por un vínculo de armonía, relación y equividibrio y cada término, ocupaba el lugar señalado en el conjunto cósmico. Todo se resolvía en la medida, en el estatismo, en lo perfectamente hecho, de una vez por todas.

Su concepto de la forma, es un símbolo de su concepción vital. El poder ordenador que la forma tenía, le confería a la realidad una ordenación permanente y definitiva "busca el pleno equilibrio entre el hombre y el mundo, entre el sujeto y el objeto" (3).

(2).-Los grandes pensadores. pág. 5 .

(3) .-El hombre y el mundo. pág. 200. 
En esta concepción, se pretendía sacar del hombre, todo el contenido vital. Existía ura conexión inmediata del medio ambiente con el hombre y el "hombre se consideraba como imagen genuina del Universo (4).

La característica del hombre, era la inteligencia y, su grandeza, se revelaba en su capacidad de conocer la realidad objetiva que era Ia ordenación perfecta. Así, dice Euken, "la contemplación espiritual inmediata, era lo que constituía el cimiento del edificio ideológico" (5). La claridad, es la manifestación en su sentido de racionalidad y, la ley. la norma de su creación artística y de su visión cósmica que, junto con "la representación plástica de sus fuerzas mentales, constituye el punto culminante de la labor griega" (6).

La Concepción griega, se reducía así a un formulismo. Solo le preocupa la superficie de la realidad, pero se le escapaban las fuer zas irracionales $y$ originales en el desarrollo creador de la realidad. Esta armónica relación, no podía realizarse, sin el espíritu de claridad y de luz que en la lógica y en la plástica tienen su manifestación y en el firmamento griego su medio. Por eso, el objetivismo es, para Euken, como lo fué para Spaventa, la característica del pueblo griego.

La concepción de la vida del mundo griego, dice Euken, "merece grandes elogics, pero tiene un límite fijo; preséntase como acabada y cerrada sin dar cabida al mal y por consiguiente sin desarrollo de la propia esencia" (7) 10 teCa de Letras

Adinira la antiginedad griegali pera rechaza la esclavitud de los epigonos, para ponerla al frente y contemplarla con el entusiasmo de un amigo para "refrescar nuestras fuerzas como en un manantial inextingible" (8).

La diferencia de estas dos concepciones de la antigiedad, las establece Euken diciendo que la "religión mira más bien a la sutileza en la consideración de los contrastes; la cultura ideal o la Crigea a suavizar Ios; aquella concentra la vida en un punto único; ésta exige una verciadera fuerza creadora; aquella se detiene rás bien en: las debilidades de ruestra pequeñez; ésta, en la fuerza y magnitud del hombre, es decir, del hombre que se integra con el universo creando las cosas de él y para él; aquella concentra el camino para la afirmación de la vida ciertamente a través de un desmenusamiento difícil de sus elementos y de una osca negación; ésta crée poder completarse, llegar a la perfección, de seguida, imprimfiendo a la vida un vuelo audáz. (9).

(4).-La vida, su valor y significación. pág. 122 .

(5).- $\mathrm{El}$ hombre y el mundo. pág. 327.

(6) .-La vida, su valor y signiifcación. pág. 199.

(7) . - La vida, su valor y significación. pág. 199.

(8). - El hombre y el mundo. pág. 200.

(9.)-La vida, su valor y signiricación) púg. 22. 
La concepción de la vida, durante la edad media, llevó hasta lo últimos extremos la separación que en la antiguiedad se estaba produciendo entre el alma y el cuerpo. La preponderanrcia de la primera, corresponde al mundo medioeval; y la de la segunda al mundo moderno.

Para Euken, el mundo cristiano medioeval no es en modo alguno "pasado muerto" (10) como no son en general todas las épocas históricas que han realizado valores permanente y humanos. Posiblemiente, el mundo medioeval no tiene la originalidad del mundo griego, pero nos ha legado su espíritu organizador y disciplinado dentro de una cencepción unitaria.

En esta época ccexisten algunas manifestaciones del espiritu griego y cristiano, pero más que una dirección vital originada por un solo impulso y vivificada por una sola aspiración, nos muestra elementos que están "más bien unidos que conciliados" (11).

Durante este período, la investigación filosófica se inicia bajo la influencia de los neoplatónicos con Beocio y Dionicio, con Scotus Euriginia que, según Euken, prepara el pantaeismo, con San Arselmo que se orienta en un sentido racionalista, y con Abelardo cuya filosofía tiene un matiz de hondo subjetivismo moral.

La corriente sentimental se desenvuelve en la mística, donde, a una relativa disquisición ideológica, se une un fuerte sentimiento pasional. Tiene su manifestación más señalada en las innumerables herejias, que son, los precursores ty los niciadores del libre pensamiento moderno.

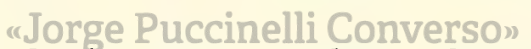

El aristotelismo de Averroes, envolvía peligrosas heregías y por lo tanto era necesario una nueva interpretación de Aristóteles que se armonizara con el cristianismo y con el dogma. Esto lo realizó primero, Alejandro el Grande y después, la enorme personalidad enciclopédica de Santo Tomás, por el sistema de la gradación serial. Esta gradación, dice Euken "concilia todos los fines y concede su derecho a cada una de las esferas sin poner en peligro el orden de todo (12).

La conciliación emprendida por Santo Tomás exigía un pensamiento poderoso y una disciplina lógica única. Establecía dos gerarquías, que se correspondía plenamente, exterior la una e interior la otra. En lo exterior existía la gerarquía esclesiástica cuya más alta situación correspondía al Papa. En lo interior o sea en el terreno racional, la cumbre de la gradación gerárquica corresponde a Dios.

Lo que Santo Tomás era para el pensamiento medioeval lo era Dante para el mundo artístico. Dante mantiene hasta la fecha muy

(10)-El hombre y el mundo. p. 151.

(11) - Las grandes corrientes del pensamiento contemporáneo. pág. 1 .

(12)-Los Grandes Pensadores. pág. 301. 
en alto el idead medioeval, y "nadie que sepa comprender el Dante, tendrá un concepto pequeño de la edad media" (13).

Pero a Eckart aquel "genial anunciador del Dios alemán del porvenir" como le llama Selliere (14) y a quien Euken debe más de una inspiración filosófica ,le dedica algunas palabras.

El místico Eckart, es, para Euken, el jefe del movimiento místico medioeval. Concibe a Dios como la esencia del universo que se desenvuelve y perfecciona con la colaboración del hombre cuya alma "tiene la misma esencia que Dios".

La característica de la edad media es el orden. Todo está perfectamente definido y delimitado, el sentido de la gerarguía lo domina todo, y el individuo solo tiene valor en cuanto está vinculado a lae organizaciones dispensadoras de espiritualidad y vida.

Se ha dicho con frecuencia, que en esta época la filosofía es sierva de la teología, pero esto es cierto, dice Euken, desde el punto de vista exterior; pero desde el punto de vista interior, es la filosofía la que le ha dado el sello a la teología.

Euken, estudia la "Reforma" como la manifestación de un nuevo cristianismo por eso la coluca después de la época medioeval y antes de la época moderna.

"La Reforma" para Euken, obedeció a un nuevo sentido de la vida y surgió como reacción a una época de sensualismo que habría provocado una oposición radical entre la vida interior y la exterioridad mundana.

La Iglesia había producido una síntesis de los elementos dispersos, como hemos anotado antes, y tenia una concepción de la vida a la que no hay que negarle "un sello de grandeza" (15). Más la excesiva organización de su vida, concluía en una rigidéz que amenazaba con las libertades del hombre y tenía que provocar protestas, de donde surgió la "Reforma".

La lglesia, que había realizado una "educación irreprochable" (16) se sentía debilitada y mal dirigida en el siglo XVI. Las críticas de Wiclef y Hus la minaban en sus fundamentos, y aún la misma Iglesia se esforzaba en reformarse.

Lutero, con su poderosa personalidad, aprovecha el momento histórico que se el presentaba; la cristiandad sobre todo de la parte norte de Europa, se hallaba inquieta y los anhelos de libertad religioea encontraron el momento propicio para manifestarse.

Entre la orientación social y pasiva de la religión o su dirección individualista y activa, Lutero opta por lo segundo y pretendiendo desvincular al cristianismo romano del primitivo, quiere que resurga en

(13)-Los Grandes Pensadores. pág. 305.

(14) -.Morales et Religions nouvelles en Allemagne. París 1927. p. 218.

(15)-Los Grandes Pensadores. pág. 317.

(16)_ " " " pág. 319 . 
sus pristinas el cristianismo primitivo; pero "la reforma que no era una restauración, sino que al contrario era una trasformación y perfeccio. namiento crea uni cristianismo nuevo" (17).

La anarquía bien pronto irrumpió por todas partes. El mismo Lutero se encarga, como más tarde Calvino de restablecer la disciplina tanto o más fuerte que la anterior $\mathrm{y}$, a la autoridad de los hombres la sustituyó por la autoridad literal de la palabra y del dato histórico; al intelectualismo escolástico lo reemplazó por otro y al espíritu eclesiástico romano por el espíritu eclesiástico protestante.

Con Zwinglio, la reforma se aclara y racionaliza, con Calvino se convierte en una organización férrea, donde es un crímen toda duda y los valores sociales y económicos adquieren un valor y un sentido religioso.

Fuertes sacudimientos se producen en una y otro rama de la cristiandad. El catolicismo se depura y el protestantismo se subdivide en una multitud de sectas. Pero el protestantismo se vincula a la civilización moderna adquiriendo así amplitud y libertad.

La reforma quizo renovar el crístianismo comunicándole un espíritu más varonil, más activo y alegré. Pero este principio de renovación se ha estrellado a las puertas de las Iglesias" (18).

Sin embargo la interiorización de la vida; su sentido dinámico de la existencia nos presenta este momento histórico "como un gran acto de liberación y como la aurora de un nuevo dia" (19).

La época moderna se caracteriza por su esfuerzo juvenil y de inquietud renovadora. A la vida de organización autoritaria en que se cstablecía la "subordinación aclaineligión de todas las esferas de la vida" sucede un impulso liberador en que la humanidad adquiere conciencia de su fuerza y de su poder, donde la vida, en lugar de orientarse en vista de los intereses ultraterrenos, se dirije al mundo que con sus misterios y atractivos reclama el trabajo del hombre.

A la vida pasiva, sucede la vida toda acción y productividad creadora.

El progreso indefinido representa la ruta a seguir, la fe en el poder y con la capacidad del hombre, sostiene sus impulsos vitales. La naturaleza y el mundo circundante era la principial preocupación de la existencia. La vida ya no descansa en fuerzas extrañas sino que se desenvuelve con toda libertad y originalidad.

En la época antigua, el hombre se deducía del cosmos. En la civilización moderria el mundo se interpreta en términos del hombre. La antigüedad, dice Euken "aportó el predominio de la forma viva; el

(17)-Las Grandes Pensadores. pág. 329.

(18)-El contenido de verdad en la religión. pág. 445 .

(19)-Los Grandes Pensadores. pág. 336. 
cristianismo la actividad moral y religiosa en las almas; la edad moderna el desarrollo y la intensificación de la fuerza" (20) .

La razón que durante la edad media era intérprete de la tradición, en esta época se le concibe como una facultad creadora que debe dirigir al hombre y a la cultura. Lo perfecto y la etapa paradisiaca que se colocaba en el comienzo de los tiempos se coloca en el fin de los mismos.

Con Bacon y Descartes, se pretende olvidar el pasado para comenzar de nuevo la investigación científica y filosófica. La razón se desliga de los fuertes prejuicios que le ataban y cohibían. Las relaciones del alma y del cuerpo que durante la edad se consideraban definitivamente establecidas; se distancian y hasta llegan a oponerse dividiéndose así la investigación moderna en dos direcciones precisas, el idealismo y el realismo.

Grandes adquisiciones y duraderos valores, ha realizado la época moderna, "pero por grandes que hayan sido los resultados de este nuevo espíritu, carece de unidad interior y por lo tanto de una verdadera sustantividad" (21). Se ha distanciado del cristianismo y la orientación racionalista con su ciencia y su técnica ha establecido un divorcio inrreparable.

A pesar de los valores realizados, la anarquía se ha producido y la separación de objeto $\mathrm{y}$ sujeto se han hecho infranqueables.

\section{Biblioteffrulo Txtras "Jorge Puccinelli Converso"}

\section{EL NATURALISMO Y EL INTELECTUALISMO}

En el año de 1885 en que Euken comienza a desarrollar su sistema filosófico, se encuentra ante dos corrientes del pensamiento que se disputaban el campo de la filosofía. La primera era la concepción naturalista y, la segunda, el idealismo intelectualista que pretendía revivir $\mathrm{y}$ orientar nuevamente la conciencia filosófica.

La concepción naturalista, pretendia desvincular tanto del hombre como de la "naturaleza, toda vida espiricuai. El mecanismo, con su ley determinista, pretendía explicar la materia, el hombre y todas las ramas del saber humano.

Se había abierto un abismo entre el hombre y la naturaleza. La teoría de la evolución creía haber salvado este distanciamiento, envolviendo todo en un proceso universal. La naturaleza como la concien-

(20)-El hombre y el mundo. pág. 300.

(21)_-El hombre y el mundo. pág. 507. 
cia psicológica se reducían a estados o elementos yuxtapuestos resultando la "vida espiritual como un fragmento de la organización natural" ( I ) .

Sólo la realidad natural es digna de estudio. La metafísica y la religión son productos ilusorios de mentes débiles o primitivas.

El realismo, lo considera Euken, en algunos de sus aspectos críticos, como eficáz, pero insuficiente cuando trata de construir una nueva realidad. Comte, posiblemente el filósofo más grande de esta dirección, cuando trata de construir su sistema, recurre precisamente a una serie de consideracicnes idealistas para poder concebir un mundo donde las relaciones naturales imperen y donde los sentimientos humanitarios tengan su asiento.

El naturalismo, ha dado a la vida mayor movilidad y actividad, pero ha condenado al hombre a ser instrumento de trabajo y la lucha entre los individuos y las clases se han intensificado, produciendo hondas divisiones entre los hombres. La solidaridad se ha roto y no existe entre los hombres un vínculo interior que los unifique en un propósito común y en ideales humanos.

Pero el naturalismo, dice Euken, es la negación de la misma ciencia. ¿Cómo podría concebirse, sin un espíritu que coordine los hechos dispersos, para poderlos unificar en leyes o en hipótesis que los comprenda?

Euken, no pretende desconocer los fundamentos sólidos en que se fennda la concepción naturalista. Sólo sostiene que ella debe circunscribirse dentro de sus yerdaderos límites y sólo estudiar la realidad exterier natural $y$ lo que en el hombre hay de proceso también natural. "Jorge Puccinelli Converso"

El naturalismo "ostenta un buen derecho cuando propugna el poder del hecho natural y sus repercusiones en el interior del alma; pero exagera este derecho y da un carácter contradictorio a la vida cuando guiere encausar toda producción espiritual en el concepto ensanchacio de la naturaleza" (2) .

I.n la investigación científico natural, el naturalismo está en su terreno "cuando plantea el problema de la vida en general parece insosterible" (3).

En la misma época en que Euken criticaba al naturalismo, Nietzche también lo fustigaba con intensa pasión cuando sostenía que, en el arte, tiene más valor la fuerza original que el saber ordenador y reproductor de la realidad; al objeto, oponía el sujeto y, a la razón, el sentimiento vital.

El intelectualismo lo encuentra Euken insuficiente para resolver

(1) - - La vida, su valor y significación. pág. 35 .

(2).- - El hombre y el mundo. pág. 146. 1926 .

(3). -Los grandes pensadores. pág. 601 . 
los problemas que la vida presente plantea. Este idealismo intelectualista, resulta esquemático, pleno de formas, pero ayuno de vida e insuficiente para esplicar la realidad total.

"Es una superficialización y volatización de la realidad". (4). Desconoce las fuerzas obscuras e irracionales que actúan en el cosmos, olvida, cuando no omite, las oposiciones, sin pretender conciliarlas o superarlas $\mathrm{y}$, realiza sus sistematizaciones esquemáticas, en el terreno abstracto y muerto. La historia del hegelianismo, dice Euken, nos muestra que el intelectualismo carece de virtualidades al degenerar, por un lado, en el naturalismo y, por otro, en el subjetivismo absoluto.

El idealismo intelectualista, al pretender someter la realidad a las formas de la razón, se le plantea un dilema; o sostener un idealismo puro y abstracto con un optimismo consiguiente o ante las resistencias que el mundo ofrece, concluir en un ecepticismo en la teoría del conocimiento y un pesimismo en el terreno moral.

"El intelectualismo, como dice Boutrux, representa el desaliento del espíritu que retrocede ante una tarea infinita y que reclama como premio de su labor, el reposo" (5). "Pero, agrega, la realidad se lo niega, no se cansa de crear, si el hombre se cansa de consebir".

"Sin embargo, reconocer las insuficiencias del intelectualismo, no es superarlo, sino contradecirlo. Preciso es reconocer su horizonte dozde se expresa con mayor o menor seguridad y necesario es incorporarlo a "una" relación más vasta para defenderse de la caída y del error". (6).

El naturalismo pebaja archombre, cel intelectualismo lo eleva por encima de sus verdaderas fuerzas haciérdolo comunmente abstracto y ajeno a toda realidad vital. Euken, no cree que el idealismo crítico pueda subsistir, es indispensable asignarle un contenido propio y positivo que comprenda la realidad total.

El racionalismo, tiene el gran valor de sostener la sustantividad del espiritu, pero es insuficiente cuando pretende comprenderlo todo por la razón.

(4).-Recuerdos de mi vida. pág. 457.

(5). - Grandes corrientes del pensamiento eontemporáneo. pág. 16,

(6). - El hombre y el mundo. pág. 124. 


\section{CAPITULO $\mathrm{V}$}

\section{LA EPOCA ACTUAL, LA FILOSOFIA Y LA HISTORIA}

Encuentra Euken, en su tiempo y en el presente una honda crisis que es necesario comprender y superar. La solidaridad no existe, la comunidad vital se halla disgregada en una serie de impulsos sin orientación y sin sentido. Existe una gran insinceridad. "Una dolorosa inseguridad reina en el conjunto de la vida, nuestra existencia espiritual vacila, nuestras relaciones con la realidad se hacen inciertas" (1).

Los individuos, ante la crisis, se recojen, el éxito exterior se considera como la única finalidad que las masas pretenden competir, en justa aspiración en las conquistas de la civilización, pero son incapaces de dirigir una mirada al proceso histórico, $y$ a las experiencias de 1 a humanidad y tienen un programa más bien negativo que constructivo.

Existen dos orientaciones de la vida. La dirección individual que persigue la emancipación del individuo y su originalidad caracteriza el proceso vital; y la otra dirección que se desarrolla en una fuerte organización y que espera de la influencia social, Cl realizar valores que sólo dentro de esta corriente cadquierer lsentido.erso"

La filosofía eukeniana pretende haber vencido las opocisiones realizando la vinculación interior entre el hombre y el mundo.

La filosofía es la llamada a dirigir este movimiento espiritual. Ha dirigido y es en sí, el espíritu de toda época de verdadera cultura en la historia; y es la fuente de toda vida.

Para Euken, la filosofía no es un juego ingenioso, sino que es el saber por excelencia que trata de comprender y abarcar la vida toda en su compleja realidad y que "responde, como dice Boutroux, a la tendencia más inmediata del espíritu universal, no es una simple afirmación de la realidad dada, es razón y a la vez es fé y es riesgo".

La filosofía no puede ser tradicional porque entonces se reduciría a la historia. Es precisamente creación de la historia; debe ser renovadora y comprender una concepción vital que sea un jalón origina! que contribuya al perfeccionamiento de la vida total.

$\mathrm{Si}$ sólo se redujera a investigar solamente lo seguro y definitivo, careceria de virtualidades venideras. Debe comprender o por lo menos encarar los problemas áxduos y arriesgados y tener así significa-

(1).-El hombre y el mundo. pág. 15. 
ción para la humanidad y la cultura, si no quiere convertirse en una "filosofía burguesa". Su tendencia hacia el todo no es producto de una adición, sino de la realización hacia una formación autónoma y nueva. No es síntesis, sino "un nuevo modo de ver las cosas" (2).

La ciencia constata hechos, la filosofía es dinámica y se dirige hacia los valores ideales. La ciencia, procede por análisis, la filosofía por síntesis creadoras que a su vez aclara la investigación de la realidad. La ciencia y la filosofía ni se contradicen, ni dependen la una de la otra, sino que se completan y se conjugan en una extrecha colaboración. En verdad, dice Euken, no sólo necesitan las ciencias particulares de la filosofía; sino la filosofía de las ciencias particulares. Pues sin una consideración del todo, la ciencia se encuentra desarmada ante la infinita variedad que ofrecen los hechos de la naturaleza" (3).

La ciencia, no es concebible, como constatación de hechos, si no tiene el espíritu filosófico que los coordine y forme las hipótesis creadoras. La filosofía y la ciencia son manifestaciones de una misma realidad.

El proceso que sigue el espíritu en el conocimiento de la realidad se ha invertido en la época actual. Antes se creía que procedía por análisis, hoy se sabe que se orienta por síntesis. Por eso la filosofía de Euken, se inicia por la concepción vital y total de la realidad, para después diversificarse en la realidad inmediata. Su filosofía es una filosofía de la vida.

La filosofía, no pretende ser una concepción de una verdad absoluta y que sus conquistas sean definitivas como la filosofía perennis. Es una realización histórica. Deja de ser una investigación de escuela para convertirse en Touna creación llifalnDDebe" emerger de la vida del espíritu, pero a su vez acrecentarla por medio de elaboraciones originales, haciendo concientes los motivos fundamentales de la época e impulsando el movimiento vital.

No es posible desligarse del pasado, pero tampoco repetirlo. En la historia se realiza y actualiza la vida espiritual.

La historia en su totalidad, es un desarrollo indefinido que los hombres del presente están llamados a acrecentar.

Para Euken, como para Hegel, la historia es la imprescindible "introducción del presente espiritual" (4) La diferencia que los separa es, que para Euken, el suceder histórico no es como para Hegel la manifestación de un proceso abstracto y dialéctico, sino que pleno de contenido vital, representa la manifestación temporal de la vida absoluta.

La historia se desenvuelve en el tiempo, pero sus contenidos esen-

(2). -El hombre y el mundo. pág. 319 "

(3).- " " " " " " " $\quad " \quad$ " 
ciales son intemporales, por eso es preciso "pasar de la considerzción histórico temporal a la historia espiritual". Es preciso vivir el pasado, recoger las realizaciones esenciales y reintegrarlo en el presente, realizando después una ascención de perfeccionamiento y supcración.

Así la historia es concebida de una manera inmanente, como la manifestación temporal de la vida cósmica adquiriendo así amplias proyecciones. "Hace falta de elevarse a la visión de conjunto, juzgar y festacar los valores perraventes" (5).

Euken rechaza el historicismo delicuescente que pretende resolver todos los procesos históricos en el desvenir temporal concluyendo en un relativismo abscluto. Deja de ser la historia una sucesión cambiante, para convertirse en el medio de la realización de un contenido espiritual.

Spéngler que es una de las personalidades más salientes de este movimiento, contradice su tesis fundamental cuando sostiene el relativiemo histórico; pretende interpretar, él, Spéngler, hombre de una cultura y de una época, interpretar otras culturas, sin desvincularse de la historia y ser un personaje trascendental. Es que, en el fondo, no con su teoría, sino con los hechos, está reconociendo la manifestación absoluta en cada cultura, destacándola en su investigación histórica.

Las realizaciones seper-históricas de la historia no son un pasado muerto, sino eterno presente del gue el hombre no se puede desligar.

La concepción histórica de Euken, es arisîacrálica, porque la élite realiza y dirige el movimiento vital, orientación que después ha tenido una enorme influencia en la filosofia posterion t En los grandes pensadores, en las poderosas personalidades, en los héroes que dijera Carlyle, es donde se encuentra $y$ manifiesta en toda su profundidad, la historia espiritual. Lo que para Rickert, es la selección de la historia, es para Euken la "tendencia a segregar del flujo de los sucesos algo dura¿ero" o sea la selección de lo esencial y eterno.

Los símbolos de la historia, son los grazeles individualidades que encarnan aspiraciones y conquistas del momento históricos, unas veces, como conciencia de la época, otras, reaccionando contra el medio, cuando no, precisando las corrientes inconcientes o subterráneas de un pueblo o de una cultura. Por eso, dice Euken "hay en la histercia considerada desde el punto de vista espiritual, indicaciones, incitaciones, posiBilidades que tienen necesidad de ser asimiladas y verificadas a fin de devenir para nosotros plenas realidades" "Elevarnos sobre lo histórico es nuestro fin, pero solo podremos lograrlo sumergiéndonos en la historia".

Si la filosofía de Euken, está íntimamente vinculada a la historia y si en la historia tiene su expresión. ¿Puede considerarse su filosofía,

(5).-El contenido de verdad de la religión: pág. 48 . 
un sisstema, o simplemente una dirección vital, cuyos contornos son imprecisos y cuyo desarrollo es libre?.

Euken, es uno de los iniciadores de la filosofía de la vida y por tanto de la filosofía insistemática. De él podría decirse, lo que Rickert dice de la filosofía de Simmel que es "antisistemática por sistema", Euken, rechaza la concepción filosófica como un sistema en el sentido que la concebía Hegel, como algo acabado y concluido. El concepto biológico de la vida, se extiende al espíritu, expresando la manifestación más señalada de su superación, más que oposición al intelectualisino. En esto se anticipa a la filosofía anti-intelectualista posterior.

No pretende, por esto Euken, desvalorizar los sistemas. Sólo corstata que constituyen organizaciones racionales, si bien interesantes para la comprensión de las ideas, insuficientes para resolver en él toda la filosofía de un gran pensador. Si falta el contenido vital el sistema es inútil, cuando no artificioso. Por eso cree Croce que el concepto de sistema envuelve la idea de algo estático y lo sustituye con el concepto de "sistematización histórica".

Euken, dá una dirección, plantea problemas que sólo pretende insinuar en sus obras. Como dice Le Roy de Bergson, la filosofía "quiere ser un camino tanto o más que un sistema" (8). Y Euken podría suscribir lo que Bergson expone en la introducción de su "Evolución Creadora" cuando dice que su filosofia "necesitará del esfuerzo aunado de muchos pensadores (y de no pocos observadores) los cuales unos a otros, se completen, se corrijan $y$ se rectifiquen" $y$ agrega "que no aspira a resolver de golpeolos grandes problemas, aspira solo a indicar el método y en algún punto esencial dejax entrever la posibilidad de su aplicación". (9)

La filosofía no la concibe Euken como un sistema, pretende ser una orientación de complexión orgánica que en constante dinamismo creador se renueva perennemente. Es una conquista a la etemidad.

\section{CAPITULO VI}

\section{LA SUPERACION DEL GRADO NATURAL Y ANMICO}

En la vida natural, el instinto domina y dirige la adaptación de los seres y tiene su más alta manifestación en el instinto de conservación.

Más tarde, con el desenvolyimiento del pensamiento en el hom-

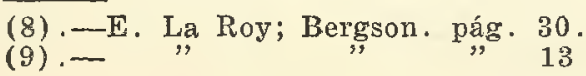


bre, se plantea el problema de si debe o no vincular su existencia al instinto de conservación. El occidente, dice Euken, lo ennoblece por medio de la propia acción; el oriente pretende anularlo en la naturaleza. El sentido artístico del griego, la interpretación moxal del cristiano y la orientación dominadora del hombre moderno sobre la naturaleza, nos advierte que "todos ellos anuncian incontrovertiblemente un movimiento de vida sobre la naturaleza".

La vida natural con su interpretación mecanicista, no sólo domina las manifestaciones de la realidad material del mundo, sino que también comprende al hombre en lo que tiene de natural y exterior. Pero la originalidad y libertad que nuestro mundo interno nos revela, más que como problema se nos manifiesta como un hecho inmediato, donde se demuestra que somos capaces de acción, que nuestro mundo interior nos impulsa en un sentido renovador, certro, en donde se contraponen en lucha trágica, los instintos naturales que tienden a la conservación del individuo, e impulsos generosos que los niegan y que lo destruyen en aras de los grandes ideales humanos. Por el trabajo ciertífico, por la experiencia moral y la actividad artística, nos afirmamos y distinguimos del acaecer mecánico y ciego de la naturaleza y, dominándola, le imponemos un nuevo ordenamiento y vitalidad.

La libertad, concebida como un hecho originario e interior, tiene resistencias y oposiciones. Estas resistencias, producen una constante reacción reafirmando la acción liberadora y dándole "un carácter trágico" donde irrumpe ux impulso original de vida.

La naturaleza, en su sentido mecanico, no explica su esencia evolutiva. Sólo interiorizándola, concibiêndolancomsola manifestación exterior de una vida interior u autónoma, adg̨uiere sentido. Así, el grado natural es insuficiente para explicar el sentido vital de la existencia y se hace indispensable superar este grado aunque para Euken "la naturaleza y la vida espirituaí no se oponen" (1) .

La vida natural, deja de constituir el todo, como lo concebía el naturalismo, ni tiene la misma pasiva que le asignaba el idealismo intelectualista para convertirse en el primer grado de la vida ascendente espiritual. De objeto que debe ser comprendido, se convierte en realidad viviente y dinámica que tiene una misión que realizar en el proceso cósmico universal. No ve Euken en la naturaleza, una realidad estática, sino que la concibe como una vida que crea, se ennoblece y sobrepasa los límites de la mera conservación.

Euken sostiene que la naturaleza es un grado inferior de la vida, por eso todas las religiones así lo establecen y considera que solo "una lamentable debilidad y medianía del pensamiento, puede hablar de una religión inmanente" (2).

(1).-La vida, su valor y significación. pág. 155 .

(2).-El contenido de verdad de la Religión. pág. 185. 
El hombre, desenvuelve sus actividades vitales en la naturaleza, pero trasciende de ella y proyecta su vida espiritual en el infinito. También en la naturaleza, dice Euken, "sirve en cierto modo a los fines de la vida espiritual" (3).

La vida espiritual como veremos más adelante, realiza según la filosofía de Euken, un proceso tríaidico como el espíritu de Hegel. En el primer momento, se identifica con la naturaleza, en el segundo se opone, y en el tercero se compenetra colaborando, la vida sensible y natural, al desenvolvimiento de la vida total.

Euken, es uno de los primeros filósofos que en su crítica histórica ha dado una gran importancia a Goethe. Al explicar el sentido de esta vida espiritual le sirve de ejemplo y símbolo la vida y la obra de Goethe. Así la vida del poeta, como su obra, no se reduce a la imitación de la realidad natural, no es tampoco el reflejo de su mundo subjetivo; es más bien una unidad superior y viviente que comprende los dos momentos anteriores en uno superior y total.

La vida anímica, se desarrolla en el tiempo, pero al vivir el hombre, siente su fugacidad y entonces el estado inmediato se compensa con la intimidad espiritual que va más allá del estado anímico. Poner la vida del espíritu, en la existencia del alma, dice Euken, es destruirla relativizándola y disolverla en una infinidad de estados anímicos sin una unidad que los comprenda, sin una sintesis que los unifique.

El hombre, en las concepciones religiosas de la vida era el centro y fin del universo. Enlas concepcionesmodernas es reducido a una partícula atómica sin significacióncén el li espacio ilimitado, más Euken no pretende hacer del hombre el constructor del universo como lo hace el idealismo intelectualista, sólo lo considera como el copartícipe de la vida universal y cuya colaboración es indispersable para la actualización del espiritu y la realización del todo.

La vida anímica participa del grado natural, pero representa una etapa superior en la vida universal. Es el centro de donde irradia todo esfuerzo y es indispensable para que no se disuelva en un atomismo anímico concebirlo como formando parte de un mundo superior. Sólo en la concepción de una vida espiritual, como parte de un centro superior, es posible darle su verdadero valor sobrepasando las manifestaciones de la mera individualidad. Es así como se produce "la posibilidad de que la vida del conjunto se actualice en el alma, y que esta tienda a ella y se enriquezca por ella" (4). La vida aninica adquiere una unidad superior a sus estados transitorios y a sus propiedades naturales.

Según Euken, la distinción que hace entre la vida anímica y la viàa espiritual, le conduce a establecer un nuevo método para que sea posible establecer esta distinción y es el método noológico.

(3) - - El contenido de verdad de la Religión. pág. 128.

(4). - El hombre y el mundo. pág. 353 . 
En Alemania, se ha producido a este respecto una literatura muy abundante, para explicar su carácter y posibilidades. Sin embargo la distinción de alma y espíritu es tan antigua como la filosofía y Plotino ya la establecía.

Euken, distingue el procedimiento psicológico del procedimiento noológico. El primero, parte de lo disperso e individual; el segundo de las visiones de conjunto de la síntesis vitales. Al conocimiento de lo vario, opone el conocimientao de lo uno, a la contemplación pasiva, sucede la orientación activa partiendo del conjunto considerado como actividad. "El método noológico, dice Euken, comprende lo particular de una concepción total de la vida; el principio explicativo no viene de fuera, sino que está presente interiormente y es, en último término un hecho y una experiencia." (5).

Hay que concebir este métocio noológico, como la aprehensión de lo dinámico y tiene por objeto designar, como dice Lalande, "la ciencia de la vida creadora del espíritu" entendiendo la palabra ciencia en un sentido amplio (6).
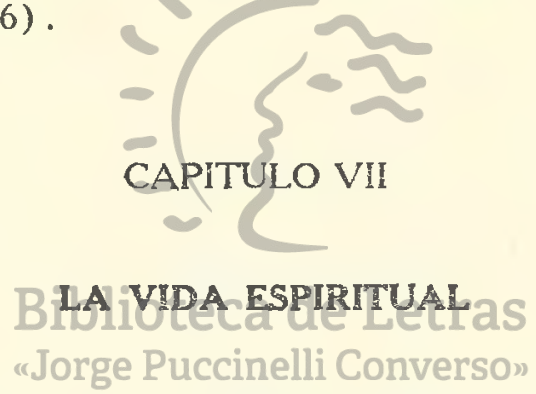

El hombre, aunque vive en la naturaleza y su espíritu está en extrecha relación con ella, muestra caracteres que lo distinguen y que establecen una relación de superioridad. La creación y perfeccionamiento que realiza y la existencia de una sustantividad interna que se contrapone al objeto natural y al sujeto anímico, constituye un reino interior independiente y una realidad esencial.

La vida interior, forma en el individuo una sustantividad propia. que se caracteriza por su unidad y universidad. Comprende los sentimisntos de amor y simpatía, fuentes de las creencias religiosas y de los impulsos generosos de la humanidad. La felicidad y la dicha, se hacen insuficientes para justificar su dirección. Sólo adquiere valor, lo que nos relacione con el todo, "por que la vida humana, solo adquiere un carácter espiritual, por su fundamentación en una actividad creadora" (1)

Euken, en la concepción de esta vida espiritual, no procede por análisis, sino que parte de las visiones de conjunto. Interiorizándonos

(5) -- El contenido de verdad de la Religión. pág. 137.

(6).-Lalande.-Vocabulaire de la Philosophie. Tomo II. päg, 519.

(1) .- El hombre y el mundo. pág. 92 . 
dentro de nosotros mismos, captaremos el sentido de esta vida, que surge tanto del sujeto como del objeto $\mathrm{y}^{\prime}$ que es todo dinamismo y actividad.

El hombre se apropia de esta vida en el acaecer histórico, según sus condiciones individuales y la fuerza de su personalidad. Una vida, así considerada, de la vida interior del espírirtu, "surge la luz frente a la oscuridad, así como la fuerza frente a los obstáculos" (2). La filosofía, debe insinuarnos sus lineamientos y su dirección aunque su desawrollo no tenga límites, ni momentos estáticos en su desenvolvimiento.

El espíritu, según la concepción de Euken, no es una entidad estátỉca, sino un proceso dinámico, es vida, no es un lento discurrir, sino lucha y contradicción. Pero al vincularnos a esta vida interior, se nos presentan las oposiciones con mayor nitidéz y "al perezoso estancamiento, suceden una lucha leal y franca" (3).

La vida es concebida así, como lucha, entre motivos opuestos, como duda. El sucesor vital se semeja a un drama donde los elementos trágicos adquieren señalado relieve y pujanza. La historia, es de esta manera, posible, y el tiempo, el antecedente de una nueva lucha que no tiene por objeto el bienestar del/individuo sino "la justificación de los derechos de la vida espiritual, en la humanidad". El esfuerzo, la lucha, no tiene un carácter accidental ajeno a los motivos y al devenir espiritual. Es un realizarse y una colaboración a la vida del todo.

La vida, es un contínuo devenir, una perpetua creación; pero para Euken, el devenir no es como para Bergson, mudable y cambiante donde todo se crea y se destruye sino que, apesar de surgir de la oposición y de la lucha irrumpe de su proceso unanialason sustantividad propia y sus conquistas no son temporales sino que sobrepasan esta condición y se elevan a la categoría de formaciones intemporales y eternas. Es una espiritualidad "combatiente" que debe tener presente "el peligro, la exitación y aún la duda, si ha de dar plena tensión a la vida" (7).

El espíritu es concebido como acción. Sólo en relación con el espiritu, es que adquiere sentido y dirección la vida de la naturaleza y del hombre.

La vida del espíritu, se realiza en el hombre y en la historia y no proviene del exterior sino de una unidad que surge desde el interior de nosotros mismos inspirando el trabajo del hombre, dándole un valor universal y una conquista para la eternidad.

La unidad de la vida, es de carácter universal, es decir, comprende a la vez el todo. Esta universalidad, no es una universalidad abstracta, sino plena de contenido y de realidad. Se manifiesta como una

((7). - El hombre y el mundo. pág. 299. 
fuerza inmanente que surge del interior, pero que trasciende de las realidades individuales, aunque en las creaciones personales adquiere valor y fuexza. Es un impulso activo, que está en constante creación, que exije la apropiación del hombre y adguiere en las grandes personalidades su relieve más señalado.

"Procuremos, dice Euken, concebir la vida en sí misma, sigiéndola en su propio moviniento, reconociendo en ella conesiones" y pudiendo "aportar una explicación relativa a la significación y valor del universo" (8) Nuestra misión es ascender en la escala de los valores desarrollando nuestras posibilidades interiores que están vinculadas al todo, pero esta vida, no es una posición, sino una conquista; reclama una decisión, precisa un impulso activo y creador que sea todo acción y que terga una funderšnentación ética.

El perfeccionamiento no se realiza "en una línea recta sino a través de ciferentes giros y encrucijadas" (9).

La característica de la vida espiritual, es la de ser interior e independiente. Pero esta independencia, no hay que concebirla como algo espacial y exterior, sino combalgo diverso y cuelitativo, cuyas posibilidades es necesario realizar y cuyos resultados y adquisiciones sobrepasan la coridición meramente temporal.

La vida espiritual va más allá de lo humano, aunque en lo humano se actualiza yon las grandes personalidades adquiere señalado relieve. Esta vida, es así un acto "de auto-profundización y de auto-posesiani, hảys queverificar y conyertir en hecho propio lo que en el fondo se posee ya, hay que llegar a ser, como dice Píndaro, lo que es", (10). La contradicción es consustancial a la vida del espiritu y es lo que produce una tensión tal, que la dinamiza, la convierte en constante actividad, orientándola en un esfuerzo de supe ración constante y de vida.

Al grado primario de la vida, que está caracterizado por la na turaleza indiferente a todo valor y sometida al determinismo; superando el segundo grado de la vida caracterizado por su ezistencia anímica, individual, ajena a toda comunidad vital, sucede la verdadera vida que comprendiendo las dos grandes anteriores realiza una nueva adquisición y que surge con caracteres originales y nuevos. La vida espiritual acciona y reacciona en los individuos que son centros de actividad y de vida.

La dificultad que la lucha produce en la concepción de la vida, no es motivo suficiente para desterrarla como producto de oposiciones que ecoxisten. Con olvidarla o suprimirla en una filosofía, no se le aisla del proceso vital, ni se suprimen las oposiciones en el desenvol.

(8).-Ia vida, su valor y significación. pág. 203.

(10) - " hombre y el mundo. pág. 149. 
vimiento. Nos inquieta y preocupa esta situación, pero "la misma ertrañeza que nos produce ésta obscuridad equivale al comienzo de una iluminación".

La posesión de la vida espiritual en su unidad vital donde se confunde el objeto y el sujeto, como la unidad viviente en la obra de arte es "más una tarea que realidad" que en su dinamismo resiste a toda definición y a la pretensión de expresarlo de una manera definitiva. La lucha que se libra es precisamente para desligar los contenidos espirituales de la condición meramente humana, realizando el hombre su piopia esencia que es la realidad interior de la vida espiritual.

Esta concepción hace del hombre un centro vital que se desenvuelve, un foco de energía latente que se pexfila. El sentido de contraste que inspira la filosofía de Euken no hace la vida fácil, pero sí más ri ca, más movida y más grande, despertando en el hombre el problema del mundo y el deseo de una nueva vida que sea como nuestra propia esencia". (2)

La característica de esta vida, es la de ser de carácter ético, endiendose la moral no como un conjunto de nomas pre-establecidas sino como la elevación de la propia vida, respondiendo a un impulso interior y esencial.

La interioridad que la vida produce, no se realiza sólo en el individuo aislado, sino que exije la colaboración de la humaniaja toda. La esencia de esta vida es constituir un ser que se encuentra no más allá de la actividad, sino dentro de ella, resolviéndose en creación y vida. Piero la creación no está predeterminada por el pasado, sino que exije que el pasado sea apropilido ynactualizado en cada uno de nosotros, no como una aceptación sino más bien como producto de una decisión y apropiación interior. El Hombre ante la historia no déce ser un observador sereno sino vivir la vida del pasado en el presente.

La vida espiritual "no constituye un ser inerte, sino una vida infinita capáz de hacerse concreta ciertamente, en una existencia espiritual" (3).

No tienen una explicación clara, en la filosofía de Euken, los elementos que intervienen en las oposiciones y contrastes que la vida im plica, pero, apesar de lo abstruso de algunos pasajes se puede decir que son producidos no por realidades ontológicas que se contrapongan, sino por oposiciones de carácter moral.

El mal aparece en algunos pasajes de su obra como el promotor de esta acción, pero carece de la precisión que tiene, por ejemplo, en la segunda etapa de la filosofía de Simmel.

El problema que se nos plantea, después de las breves orientaciones que hemos dado sobre la filosofía de Euken, es saber si su filo-

(2).--El contenido de la verdad en la Religión. pág. 183.

(3). - La vida, su valor y significación. pág. 117. 
sofía, es monista o dualista. Los críticos de su filosofía están algo divididos a este respecto, pero es necesario analizar estos dos aspectos del problema.

La filosofía de Euken es indudable que tiende a una concepción monista Llel cosmos. La realidad esencial y eterna, para Euken es el espiritu que se desenvuelve a través de toda la realidad. Es una corriente que todo lo penetra y vivifica, es la posibilidad de toda actualidad, lo virtual de toda realidad. Sin una concepción monista, no sería explicable la investigación de la esencia absoluta de las cosas, y del universo $y$ al absolutimo de los tiempos modernos, opone Euken "Io eterno tanto hecho como tarea, hecho como fundamento e impulso de toda vida espiritual, tarea como término y perfección" (4).

Al concebir la vida como contraposición y lucha tenemos que sostener con el Prof. Oesterreicht que "desde este punto do vista Euken es ơualista" (5).

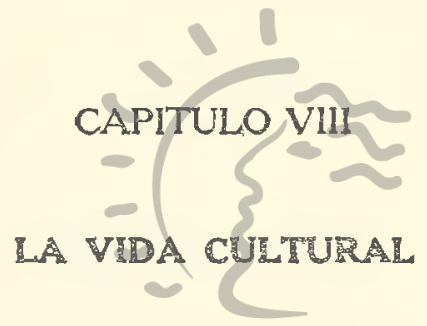

En la vida culturali lencuentra Euken, quelseSdisputan la supremacía dos concepcioneşogue sel contraponen. La corientación dirigida a la cultura social y la dirección individualista de la cultura.

La cultura social, tiende a mejorar las condiciones de la convivencia social y con los progresos materiales y las conquistas técnicas, pretende satistacer todas las necesidades de la naturaleza humana. Sus exigencias se dirijen preferentemente al exterior, lo mismo que la acción y sus conquistas sólo se limitan al sobre haz de las cosas. Esta cultura, dice Euken, "es incapáz de constituir por si mismo un valor para la vida del individuo, su pleno desarrollo, sin las limitaciones de la cultura social, si bien estas concepciones tienen poderosas razones para propiciar el perfeccionamiento del individuo, es limitada en su concepción.

A la cultura exterior, le llama Euken también, cultura existencial - comedia culiural, en oposición a la cultura esencial que es la verdadera cultural y que se caracteriza por los fuertes vínculos interiores, que se relacionan en una verdadera comunidad vital. Sólo fundada la cul-

(4). - - El hombre y el mundo. pág. 118.

(5).-T. IX. Oesterreicht. Die Deutsche Philosophie des XIX Janrhundersts uno der Gegenwart, Berlin 1923 pág. 580. 
tura en la vida espiritual, tiene una verdadera unidad y la cultura material adquiere sentido y dirección.

En la historia se distinguen para Euken, tres clases de culturas. La cultura artística, que corresponde al pueblo helénico, la culturática que esća representada por el cristianismo, y la cultura dinémica que es la fiel expresión de la edad moderna. La primeza, se caracteriza por ou concepción armonicsa de la vida y cuya existencia está matizada de cierta alegria y poder considerable, pero las contradicciones y dudas le hacen bien pronto vacilar. La vida inmediata carecía de sentido y se necesitaba de una nueva realidad vital superior, que la realizó el cristianiomo. Pero ésta nueva cuitura se separó demasiado del mundo, lo transcendentil la atraía con fuerza irresistible y la vida del mundo se resentía de su postergación y olvido. El trabajo se desvalorizaba y las únicas preocupaciones que tenía los hombres, se orientaba hacia la otra vida.

Los tiempos madernos concentran en la fuerza y poder del hombre, todas las posibilidades para un trabajo efictente y certero. El dinamismo, que es la característica de esta época es insuficience para satisfacer las exigencias del hombre y limitando su acción a lo meranente temporal y al "no dar nunca una posesión superior al tiempo, llegará a ser para el hombre absurda e intolerable". (1)

El hombre actual ge encuentra, dice Euken, ante estos tres tipos de cultura y no puede preferir el uno o el otro, porgąe las dificiencias de la uno, no se compenia contlas otrabsino que exije una niveva concepción.

Las distintas "Jiluras huccinelli Conversp" ro su unión es insuficiente para estableer una verdadera cultura actual. La única cultura de verdadero valor es la que es fiel expresión del momento histórico y es sostenida y fundamentada por la vida esencial.

La cultura gue se fundamenta sólo en los progresos técnicos, la llama Euken, cultura del trabajo. La cultura es una elaboración eepiritual que no se agota en las formas exteriores, sino que exije la vivificación interior de una vida espiritual. Es la creación de la colectividad y representa frente a la naturaleza, un mundo de valor es de conteztura espiritual. Al trabajo cultural están llamados todos los hombres, pero son pocos los que la producen en un grado elevado. Solo es grande cuando se establece en ella una unidad, por eso dice Euken que toda verdadera cultura es "un esfuerzo de la humanidad por la unidad de su vida y esencia" (2).

Euken, en su obra distingue, lo que Spengler habia de distinguir después, entre cultura y civilización, llamando civilización al prozreso exterior y cultural, al proceso social que inaugura una nueva realidad

(1) . Las grandes corrientes del pensamiento Contemporáneo pág. 311.

(2).-El contenido de verdad y de la religión pág. 109. 
vital como manifestación de un espiritu original y nuevo. Sin embargo, en el uso de estas dos expresiones, no guarda la distinción de una manera precisa.

Si concebimos a la cultura como la manifestación de la vida espiritual, independiente, "se nos ofrece un camino practicable, puesto que, con la autonomía de la vida espiritual tal como la defendemos, la civilización que sirve a su florecimiento, está emancipada de lo que hay de superficialidad en las tendencias humanas". Esta unión del hombre con la cultura, no es algo concluído y definitivo, sino que exije una constante renovación y convierte a la cultura en algo más que una adición de lo humano a la naturaleza, adquiriendo profundidad y hondura.

\section{CORCLUSION}

La filosofía de Euken, tiene otros dos aspectos de su filosofía que si bien son de gran interés para un estudio que pretenda ser exaustivo del filósofo, no lo son para el objeŕo que nos hemos propuesto o sea conocer la orientación neo-idealista de la filosofía de Euken. Estos dos aspectos son: su filosofía religiosa y su concepción del Cristianismo. Alguros autores, como Hoffding, le dan una capital importancia a la filosofía religiosa, pero elio se explica, si se tiene en cuenta que su "filosofía contemporánea li doles túcensayo desistendatización de doctrinas, sino sólo estudios äislados sebra da fllosofiarde la época.

La obra de Euken, se reclama de una intensa inspiración platónica, en su sertido de lo eterno. El misticismo de Eckart, en los tiempos modernos, el activismo de Fichte que junto con su sentido apostólico, le ha conferido a Euken su vibrante actividad espiritual.

Hegel, influye también en su concepción histórica del universo y Krausse en su sentido del yo activo y transcendente; pero esas influencias sólo prueban la continuidad histórica de la filosofía y dejan a salvo gus innumerables disquisiciones filosóficas precursoras de muchos aepectos de la filosofía posterior.

La obra de Euken carece de una verdadera fundamentación en una teoría del conocimiento y aunque en su obra ha intentado hacerlo, carece de una verdadera eficacia filosófica .

La excesiva preocupación histórica, creemos con Kulpe, que ha contribuício a gravar sobre su pensamiento, limitando su concepción vital.

La obra de Euken, ha tenido una gran influencia en Alemania y fuera de ella. El primer período de la filosofía de Max Sheller, en la filosofía pedagógica de Kesseler y de Lesser, y la filosofía de Claw tienen muchos puntos comunes con la filonotía de Euken y pueden 
considerarse de su escuela a Otto Braun, Budde, Oldendoff, Einhorn, Dorner y Hoffman.

Euken, como gran parte de la filosofía contemporánea de Alemania, ha continuado la filosofía de la vida que Nietzche había iniciado pero dándole un carácter más interior y espiritual. Inicia una filosofía de un matiz marcadamente anti-intelectualista, sin llegar a las exageraciones que posteriormente ha llegado esta filosofía. En su concepción histórica, se vincula fuertemente a la escuela de Baden y especialmente con Windelband, sólo que el pensamiento de Euken, es activo y el de Windelband contemplativo; el segundo ve el absoluto en el valor super-histórico de la historia, el primero concibe el absoluto como una tarea, como una conquista, en parte realizada, pero que exige una constante renovación y lucha.

Quien dirija una mirada por la obra filosófica de Euken, podrá encontrar en el primer momento la obscura complejidad de lo exuberante, pero si se detiene en su contemplación verá que opera con gran amplitud en el panorama de la filosofía actual.
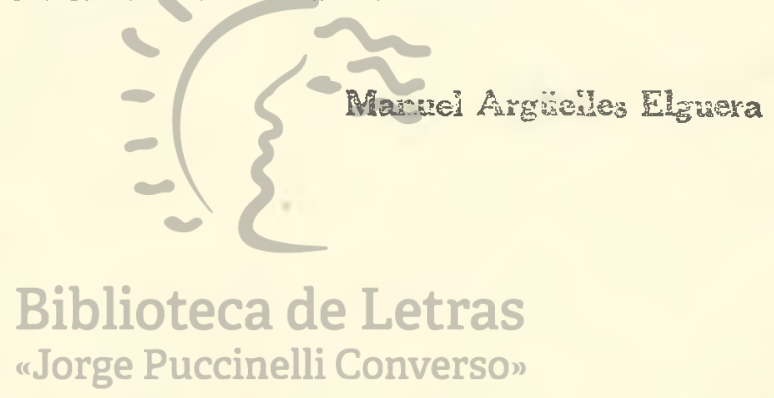

NOTA.-EI trabajo que antecede fué presentado por su autor a la Facuitad, como tesis para optar el grado de Doctor de Filosofía. 